\title{
The Nance Lingual Arch: An Auxiliary Device in Solving Lower Anterior Crowding
}

\author{
Renato Rodrigues de ALMEIDA \\ Paula Vanessa Pedron OLTRAMARI-NAVARRO \\ Marcio Rodrigues de ALMEIDA \\ Ana Cláudia de Castro Ferreira CONTI \\ Ricardo de Lima NAVARRO \\ Murilo Rizental PACENKO
}

Department of Orthodontics, UNOPAR - University of North Paraná, Londrina, PR, Brazil

\begin{abstract}
After exfoliation of the primary incisors and eruption of the permanent incisors, the dentist has the opportunity of observing closely the beginning of occlusal changes. In several cases, alterations, such as lower anterior crowding, can be prevented and treated with proper follow-up. In the mixed dentition, one of the mechanisms for maintaining space and favoring dental alignment is to preserve leeway space before permanent second molar irruption. Among the devices with this function, the Nance lingual arch helps maintaining the position of the permanent mandibular molars and incisors after a premature loss of the primary canines. This paper describes the applicability of Nance lingual arch for preserving leeway space, thus contributing for correction of lower anterior crowding.
\end{abstract}

Key Words: preventive and interceptive orthodontics, crowding, space maintainer, leeway space, Nance lingual arch.

\section{INTRODUCTION}

Dental crowding can be classified as primary, secondary, and tertiary. Primary crowding is caused by a tooth size incompatibility between primary and permanent teeth, and is generally of genetic origin. Secondary crowding occurs in the posterior area due to premature extractions of primary molars, with consequent loss of the arch length. Late incisor crowding (tertiary crowding) happens towards the end of the maximum peak of mandible growth, which coincides with the eruption of the third molars (1).

Primary crowding was later classified into two subtypes: temporary and definitive (2). Temporary primary crowding has shown a prevalence of $52 \%$ in children, and, has spontaneous correction during normal occlusion development. In this condition, the incisors erupt close to the alveolar ridge line, characterizing mild crowding. These dimensional alterations occur during and immediately after the first transitional period of the mixed dentition, and contribute to increase the dental arch perimeter, which gives a transitory feature to temporary crowding (3) (Fig. 1 A-C).

Conversely, definitive primary crowding, in which the permanent incisors erupt further from the alveolar ridge line, requires an early intervention. This type of tooth crowding may have either a genetic or an environmental origin, depending on the dental arch morphology (Fig. 2 A-F).

Three signs can be observed to identify potential crowding in permanent dentition. The first is the lack of interdental space in primary dentition. The second sign is permanent incisor crowding in the mixed dentition. The third is the premature loss of one primary canine, which can cause lack of space for lateral incisor eruption.

Leeway space represents the difference between the sum of the mesiodistal (MD) diameter of the primary canine and molars and the sum of the MD diameter of the permanent canine and premolars (4). Leeway space measuring up to $4.3 \mathrm{~mm}$ (5) can be maintained with the use of a Nance lingual arch after the premature loss of a primary canine. The function of the lingual arch is to prevent the incisors from uprighting, which may decrease the length of the lower arch. This space may be one of the

Correspondence: Profa. Dra. Paula Vanessa Pedron Oltramari-Navarro, Faculdade de Odontologia, Área de Concentração Ortodontia, UNOPAR, Rua Paranaguá, 803, apto 92, Centro, 86020-030 Londrina, PR, Brasil. Tel: +55-43-3371-7991. e-mail: pvoltramari@hotmail.com 

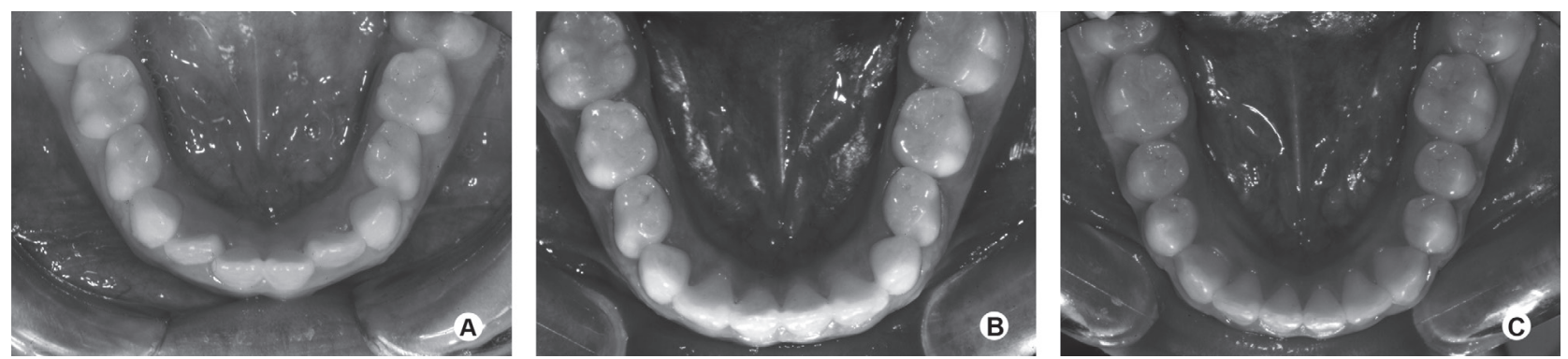

Figure 1. Lower intraoral occlusal view illustrating temporary primary crowding: lack of space for both lateral incisors (A), spontaneous alignment (B), the end of the occlusion development, without the need of any orthodontic intervention (C).
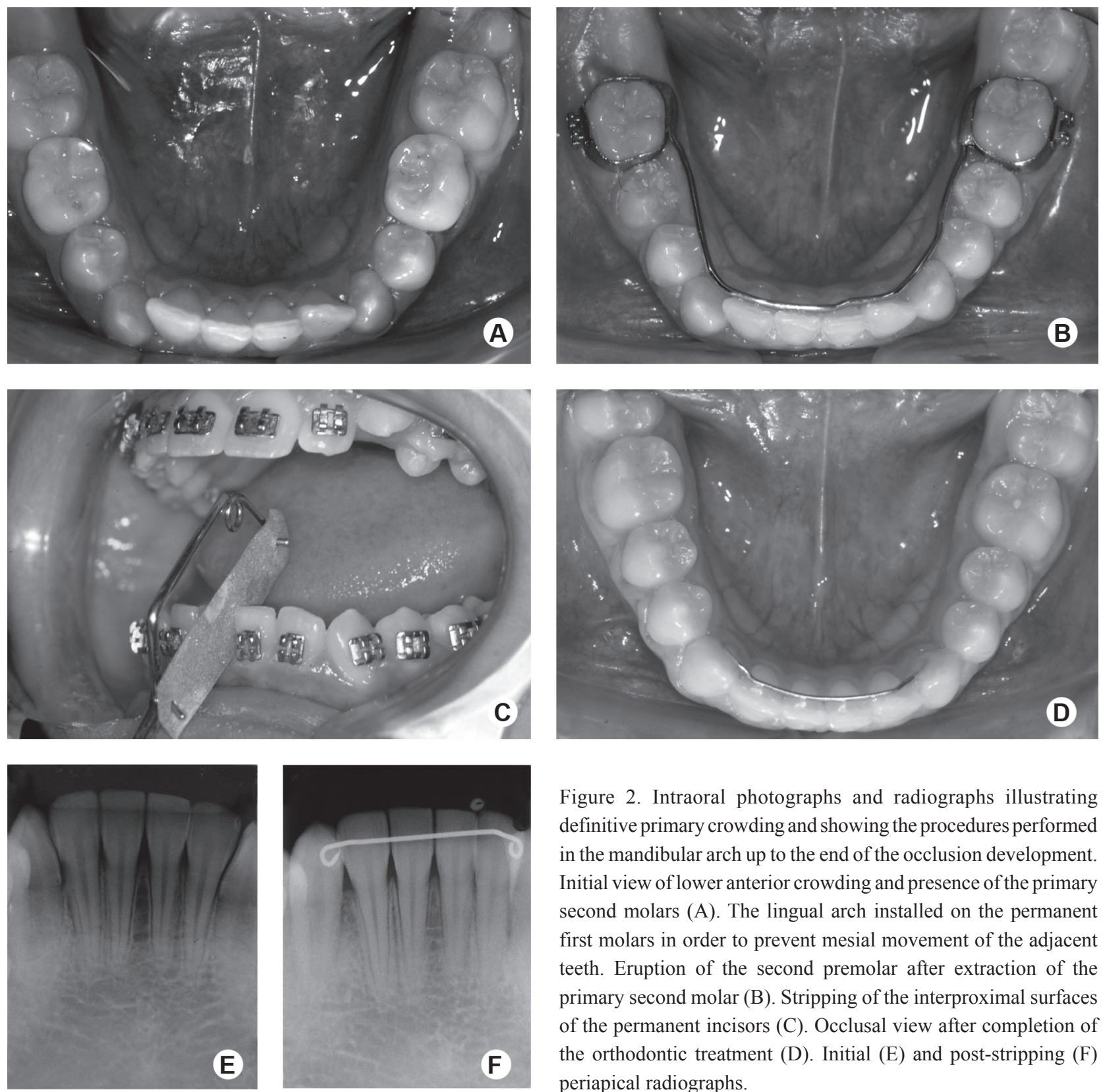

Figure 2. Intraoral photographs and radiographs illustrating definitive primary crowding and showing the procedures performed in the mandibular arch up to the end of the occlusion development. Initial view of lower anterior crowding and presence of the primary second molars (A). The lingual arch installed on the permanent first molars in order to prevent mesial movement of the adjacent teeth. Eruption of the second premolar after extraction of the primary second molar (B). Stripping of the interproximal surfaces of the permanent incisors (C). Occlusal view after completion of the orthodontic treatment (D). Initial (E) and post-stripping (F) periapical radiographs. 
reasons for which tooth crowding in the mixed dentition becomes less pronounced in the permanent dentition.

In Orthodontics, concern with the premature loss of primary teeth is justified by the space loss that could occur in the dental arch due to the inclination of the adjacent teeth towards the space left by the extracted tooth. Therefore, its permanent successor, without any available space, deviates from its eruption path and can have an ectopic eruption (6). In order to avoid the establishment of a malocclusion, a space maintainer appliance should be installed since it will hinder the migration of the adjacent teeth towards the space for the permanent tooth successor.

Among the types of space maintainers, the Nance lingual arch stands out as a fixed appliance of easy construction and hygiene, and an excellent option for orthodontists. This paper reports the applicability of the Nance lingual arch for preserving the leeway space, allowing correction of lower anterior tooth crowding.

\section{CASE REPORT}

An 8-year-old Caucasian male patient sought orthodontic care due to the premature loss of a mandibular primary canine. Additionally, mesialization of posterior teeth was observed, with consequent lack of space for the permanent canine successor (Fig. 3A).

Panoramic radiograph showed the presence of all permanent teeth, either erupted or at several developmental stages, except for the third molars, as well as the lack of space for the permanent canine (Fig. 3B). A Nance lingual arch was installed to prevent greater space loss (Fig. 3C). The interceptive stage was completed after 18 months of treatment, during which the patient was followed up regarding the occlusion development, (Figs. 3D and 3E). Later, during the comprehensive stage, the goal of the treatment took advantage of the available space for aligning, leveling and correcting small rotations (Figs. 3F and 3G).

In order to verify treatment stability, mainly due to the use of leeway space, a follow-up appointment was scheduled 5 years after the end of treatment, and was duly registered as seen in Figure $3 \mathrm{H}$.

\section{DISCUSSION}

The treatment of negative tooth-bone discrepancy can be regarded as preventive when leeway space is preserved after the premature loss of primary molars, thus avoiding tooth migration, and a decrease in the arch perimeter.

One possibility for correcting definitive primary crowding consists in preserving the arch length, by installing a Nance lingual arch, and performing either interdental stripping or extraction of primary and permanent teeth. These procedures aim to anticipate and/ or guide permanent teeth eruption towards the available posterior space (7).

In Figure 1, the spontaneous alignment of lower anterior primary crowding can be observed, and is shown to be initially in the $3 \mathrm{~mm}$ range. According to Russel (8), mild crowding is self-corrected, with no need for intervention. However, when tooth crowding is greater, intervention may be necessary, by using either selective interdental stripping or extractions, and by simultaneously installing an orthodontic appliance.

In Figure 2, definitive primary crowding was demonstrated at late mixed dentition $(1,2)$. This discrepancy (crowding) did not show any self-correction, and, interception was made by installing a Nance lingual arch associated with interdental stripping. This procedure allowed the use of "leeway space", which, in this case, was about $3 \mathrm{~mm}$ on each side. Regarding space maintenance, tooth migration, and malocclusion, Brothwell (9) verified that space preservation should only be taken into account when the succeeding tooth has less than $75 \%$ of root formation, or when there is more than $1 \mathrm{~mm}$ of alveolar bone over it. It was also observed that space loss would depend on the exfoliated tooth, mainly primary second molars; on the moment of the exfoliation, mainly if the permanent first molar has not erupted yet; and on the presence of tooth crowding prior to space loss (10).

In order to solve definitive primary crowding, Kluemper et al. (11) suggested interdental stripping or primary tooth extractions combined with the use of bilateral space maintainers. According to these authors, the space corresponding to leeway space would be 2.5 $\mathrm{mm}$ at each side of the lower arch.

Little et al. (12) studied definitive primary crowding correction and stability. This study comprised the evaluation of 25 patients at early mixed dentition (17 female and 8 male patients), 13 of whom had Class I malocclusion, and 12 had Class II malocclusion, with at least $3 \mathrm{~mm}$ of lack of space for incisors and canine teeth. The cases were treated with a Nance lingual arch, and with the use of both headgear biteplane and a utility arch on the upper arch. At the end of the treatment, 
lingual $3 \times 3$ retainers were installed and maintained for a minimum period of 5 years and a maximum period of 10 years. Stability was observed in $76 \%$ of the cases, which could be considered as a significant success rate.
The clinical case presented here demonstrated temporary primary crowding identified during the first decade of life. In this condition, the incisors erupt close to the alveolar ridge line, characterizing mild crowding,
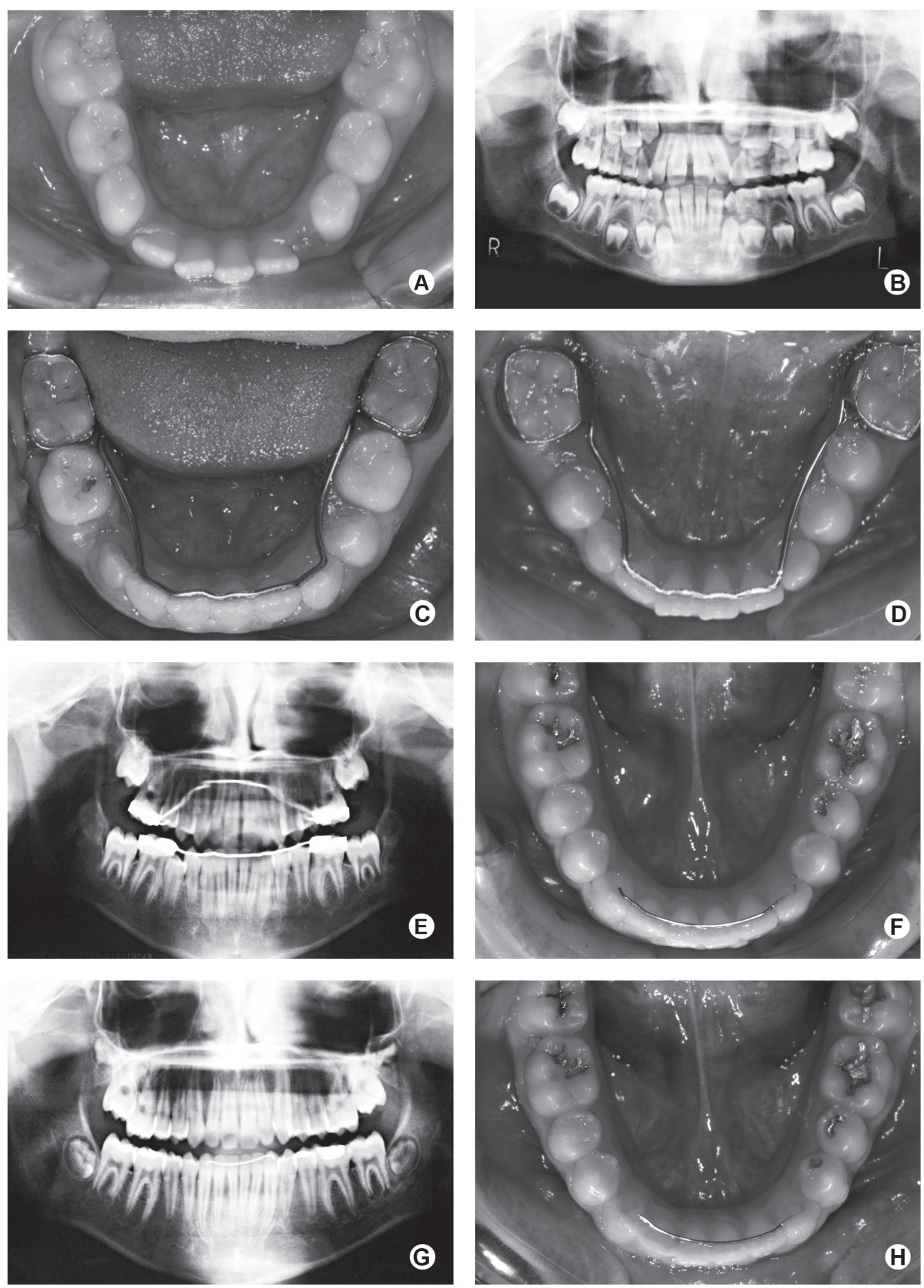

Figure 3. Intraoral photographs and panoramic radiographs showing the treatment sequence and the successful outcome (A-G). Fiveyear post-treatment $(\mathrm{H})$. 
which usually is self-corrected during normal occlusion development (13). However, due to the premature loss of the primary canine, there was a reduction of dental arch length, showing lack of space for the right second premolar, which caused secondary crowding (14). In this case, we chose to maintain the space with a Nance lingual arch for 18 months, thus coinciding with the end of the interceptive stage. After this stage, corrective treatment was performed and was later followed-up for 5 years, when stability was achieved (Fig. $3 \mathrm{H}$ ).

Other appliances could also be use to contribute to lower anterior crowding correction, such as lip bumper $(15,16)$ and Schwarz appliance $(17,18)$. However, they are not recommended in some cases for being removable appliances, thus depending on patient compliance.

Few authors have reported disadvantages of the use of a Nance lingual arch as a space maintainer, including possibility of extrusion of antagonist teeth, when considering the space left by the extracted tooth; non-reestablishment of the masticatory function; and previous history of sensibility to metallic materials (19). Despite these negative factors, the literature has recommended its use by demonstrating countless advantages that overcome all disadvantages (20).

This case report leads to the conclusion that the Nance lingual arch helps preserving the leeway space. Its use as a space maintainer was long-term effective, and the small degree of relapse observed is normally expected during the process of occlusion maturation.

\section{RESUMO}

Após a esfoliação dos incisivos decíduos e a irrupção dos incisivos permanentes, o dentista tem a oportunidade de observar o início das alterações na oclusão. Em muitos casos, realizando o correto acompanhamento, pode-se prevenir e tratar possíveis más oclusões como o apinhamento anteroinferior. $\mathrm{Na}$ dentadura mista, um dos mecanismos para manter espaço e favorecer o alinhamento dentário consiste na preservação do espaço disponível de Nance (leeway space), antes da irrupção do segundo molar permanente. Dentre os dispositivos utilizados para esta finalidade, o arco lingual de Nance auxilia a manutenção do posicionamento dos molares permanentes e incisivos inferiores, quando da perda prematura dos caninos decíduos. Este trabalho objetiva descrever a aplicabilidade do arco lingual de Nance para a preservação do leeway space, o que contribuiu para a correção do apinhamento anteroinferior.

\section{REFERENCES}

1. Van Der Linden FPGM. Development of the dentition. New York:
Quintessence; 1983.

2. Silva Filho OG, Garib DG, Freire-Maia BAV, Ozawa TO. Temporary and definitive primary crowding: differential diagnosis. Rev Assoc Paul Cirurg Dent 1998;52:75-81.

3. Silva Filho OG, Ozawa TO, Almeida AM, Freitas PZ. Serial extraction program: a contemporary orthodontic view. R Dental Press Ortodon Ortop Facial 2001;6:91-108.

4. Brennan MM, Gianelly AA. The use of the lingual arch in the mixed dentition to resolve incisor crowding. Am J Orthod Dentofac Orthop 2000;117:81-85.

5. Moorrees CFA, Chada JM. Available space for incisors during dental development: a growth study based on physiologic age. Angle Orthod 1965;35:12-22.

6. Gianelly AA. Leeway space and the resolution of crowding in the mixed dentition. Seminars in Orthodontics 1995;1:188-194.

7. Cuoghi OA, Bertoz FA, Mendonça MR, Santos EC. Loss of space and dental arch length after the loss of the lower first primary molar: a longitudinal study. J Clin Pediatr Dent 1998;22:117-120.

8. Russel B. Orthodontic treatment in the mixed dentition. J Can Dent Assoc 1996;62:418-421.

9. Brothwell DJ. Guidelines on the use of space maintainers following premature loss of primary teeth. J Can Dent Assoc 1997;63:753-766.

10. Bishara SE, Jakobsen JR, Treder J, Nowak A. Arch width changes from 6 weeks to 45 years of age. Am J Orthod Dentofacial Orthop 1997;111:401-409.

11. Kluemper GT, Beeman CS, Preston H. Early orthodontic treatment: What are the imperatives? J Am Dent Assoc 2000;131:613-620.

12. Dugoni SA, Lee JS, Varela J, Dugoni AA. Early mixed dentition treatment: postretention evaluation of stability and relapse. Angle Orthod 1995;65:311-320.

13. Little RM, Reidel RA, Stein A. Mandibular arch length increase during the mixed dentition: post retention evaluation of stability and relapse. Am J Orthod Dentofacial Orthop 1990;97:393-404.

14. Rebellato J, Lindauer SJ, Rubenstein LK, Isaacson RJ, Davidovitch $\mathrm{M}$, Vroom K. Lower arch perimeter preservation using the lingual arch. Am J Orthod Dentofacial Orthop 1997;112:449-456.

15. O'Neill J. Do lip bumpers work? Evid Based Dent 2009;10:48-49.

16. Solomon MJ, English JD, Magness WB, McKee CJ. Long-term stability of lip bumper therapy followed by fixed appliances. Angle Orthod 2006;76:36-42.

17. Tai K, Hotokezaka H, Park JH, Tai H, Miyajima K, Choi M, et al.. Preliminary cone-beam computed tomography study evaluating dental and skeletal changes after treatment with a mandibular Schwarz appliance. Am J Orthod Dentofacial Orthop 2010;138:262.e1-e11.

18. Tai K, Park JH. Dental and skeletal changes in the upper and lower jaws after treatment with Schwarz appliances using cone-beam computed tomography. J Clin Pediatr Dent 2010;35:111-120.

19. Bortolotti R, Ribeiro ATB, Barros MGL, Spinasse KG. Space maintainers in preventive and interceptive orthodontics. Rev Dent Press Ortodon Ortoped Facial 1999;4:25-33.

20. Viglianisi A. Effects of lingual arch used as space maintainer on mandibular arch dimension: a systematic review. Am J Orthod Dentofacial Orthop 2010;138:382 e1-e4.

Received September 10, 2010 Accepted May 26, 2011 